\title{
Gaming practices in everyday life. An analytical operationalization of field theory by means of practice theory
}

\section{Claus Toft-Nielsen and Stinne Gunder Strøm Krogager}

MedieKultur 2015, 58, 68-84

Published by SMID | Society of Media researchers In Denmark | www.smid.dk The online version of this text can be found open access at www.mediekultur.dk

This article investigates digital game play (gaming) as a specific media field (Bourdieu, 1984, p. 72), in which especially gaming capital (Consalvo, 2007) functions as a theoretical lens. We aim to analyse the specific practices that constitute and are constituted in and around gaming. This multitude of practices is theoretically qualified by the second generation of practice theorists, including (Bruchler \& Postill, 2010; Reckwitz, 2002; Schatzki, 2008; Warde, 2005). The empirical data are drawn from qualitative studies of gamers and gaming practices (focus groups as well as participant observations), and function as exemplary cases that illustrate our theoretical arguments. Our purpose is to analytically operationalize field theory, by means of practice theory, to enhance our understanding of digital games as new media and the specific contexts and media practices herein.

\section{Keywords}

gaming, practice, new media, field

\section{Introduction - contextualizing the theoretical field}

Media has become a basic part of our everyday lives, and therefore we have to study the field of media as an "open-ended range of practices" (Couldry, 2004, p. 4). We consider 
media use (in this particular analytical case, gaming), a practice that intersects profoundly with other everyday practices and yet as a relatively autonomous field (Bourdieu, 1984). Bourdieu's field theory "(...) was born out of an account of social differentiation developed long before the transversal operations of media's representational and categorising power became such a dominant feature of social space" (Couldry, 2013, p. 8). By transversal, Couldry means effects across different fields, effects that field theory offers no apparent way of registering (Couldry, 2013). In this article, we are interested in the productive intersections between fields and their effects, a concern that Bourdieu began to address in a nascent fashion (Bourdieu, 1998), and we seek to use and extend his theory as a "set of thinking tools" (Wacquant, 1989, p. 50). Couldry introduces the concept of "media metacapital" to zoom in on the different capital derived from media-related activities, which has increased in importance (Couldry, 2003, p. 668). Instead of taking such a top-down view on media-related activities, we adopt a bottom-up take on media-related activities. In order to do this, we turn to practice theory, which is a merging of elements from existing sociological theories, and which offers an analytical perspective on the constitution and conditioning of micro-processes in social life (Halkier \& Jensen, 2008).

Bourdieu understands society not as a unit, but as a number of small social entities, and these microcosms make up fields or social arenas that can be more or less autonomous or interrelated. Within these fields are networks of social relations between participants based on power and capital. Fields are specialized domains of practice (such as art, cooking, or gaming) with their own internal logic and governing principles that are constituted by unique combinations of capital (also meaning power). There are three main types of capital that individuals strive to accumulate because they define one's opportunities in life: economic (money and material goods), cultural (linguistic skills and cultural foundation), social (social network). In addition, there can be found a fourth, symbolic capital (the acknowledgement of economic, cultural and social capital in a specific field: those who possess more acknowledged capital possess more symbolic capital and thus, power and prestige). In this article, we concern ourselves primarily with a reworking of cultural capital and gaming capital, which will be elaborated on later.

Analytically, a field can be defined as a network, or a configuration, of objective relationships between different positions (Bourdieu \& Wacquant, 1992: 97). To further illustrate the configuration of a field, Bourdieu compares a field to a game; although a field is not the product of a conscious construction with explicit rules, it is still subject to regularities. Only players with sufficient 'know-how' and belief in the game will be willing to invest time and effort playing it. Over time, skilled players develop a 'feel for the game' or a 'practical sense' that allows them to improvise in a structured but seemingly effortless manner. Moreover, participants in the game/field compete for the "trump cards" (Bourdieu \& Wacquant, 1992, p. 98). The value of the cards changes with each game, and the hierarchy of the different forms of capital (economic, social, cultural, symbolic) as well as different, more field-specific forms of capital (such as culinary capital (LeBesco \& Naccarato, 2012) and gaming capital 
(Consalvo, 2007)), vary across the different fields. Some cards are valid in all fields, and these are the fundamental forms of capital, but their value as trump cards is determined by each field:

\begin{abstract}
We can picture each player as having in front of her a pile of tokens of different colors, each color corresponding to a given species of capital she holds, so that her relative force in the game, her position in the space of play, and also her strategic orientation towards the game, what we call in French her "game," the moves that she makes, more or less risky or cautious, subversive or conservative, depend both on the total number of tokens and on the composition of the piles of tokens she retains, that is, on the volume and structure of her capital (Bourdieu \& Wacquant, 1992, p. 99).
\end{abstract}

The analogy of a game connects our focus on gaming to field theory, but at the same time, it holds the reason and explanation for why we turn to practice theory as an enhancement of field theory: not everyone who is part of a field is there to win. Warde exemplifies this argument using tennis: some play tennis to exercise, others to uphold social relationships and others again to entertain children (Warde, 2004, p. 19). Thus, one of the essential characteristics of the analogy of a field to a game does not work when the 'stakes' of the game are not there. This point, as we will describe later on, is also very suggestive of our own area of interest, gaming in an everyday context, because gaming works as a way of conducting and maintaining social relationships. That is, the primary function is the social context and not the honour of winning. Warde compares the characteristics of a field and a practice: a field is competitive, strategic, and oriented to external goods, whereas a practice is cooperative, pluralistic and oriented towards internal goods (Warde, 2004, p. 25). In our case (gaming), social capital is at stake, though not in a competitive and intentional way (field), but as a cooperative resource (practice). Therefore, we dissociate from the theoretical conflict perspective held by field theory, and we argue that to be able to empirically operationalize field theory (that is, on a micro level), we also need to work with practices to detect what goes on in fields of non-strategic action, and in non-competitive circumstances (Warde, 2004, p. 2). Hence, practice theory widens the analytical scope and makes empirical analyses sensitive to the diversities of interactions in everyday life practices (Warde, 2005, p. 254).

Thus, considering gaming as a field consisting of capital, practices, and the way practices intersect, we find it fruitful to work with the so-called second generation of practice theorists (Postill, 2010), in an attempt to shed light on the change in power relations that new media has affected (Consalvo, 2007). Outline of a theory of practice (Bourdieu, 1977), along with prominent works by Giddens, (1979 and 1984), Foucault, (1978), and de Certeau, (1984) for example, founded what we know today as practice theory: an understanding of how social and cultural structures embedded in bodily actions contribute to the proliferation of practices and routines. Although there are vital distinctions between Giddens, Bourdieu and other practice theorists, their respective understandings of practices and 
routines in many ways converge. This convergence serves as the point of departure for the second generation of practice theorists, who through critical readings, have revised and further developed practice theory (Schatzki, 1996; Schatzki et al., 2001; Reckwitz, 2002; Warde, 2005). Among other things, this development consists of operationalizing practices in terms of applying them to the truisms of everyday life. Ann Swidler has termed everyday practices anchoring practices, "which play a key role in reproducing larger systems of discourse and practice" (Swidler, 2001, p. 90). This perspective embodies our study of gaming as a field in which practices unfold and intersect in an everyday context. The theoretical practice approach will be unfolded later in the article.

\section{The empirical context and methods}

The article is based on empirical data from a qualitative interview study, and focus groups comprising 12 informants: six men and six women, ranging from age 21 to 40, from different European countries (Denmark, England, Ireland, the Netherlands and Sweden). ${ }^{1}$ The aim of the study was to uncover why and how people play the largest and most popular subscriber-based Western massively multiplayer online game (MMO) World of Warcraft. Three couples participated in a face-to-face focus group, and subsequently, two web-based focus groups were conducted with three men and three women respectively. The recruiting of the focus group participants was theoretically informed according to three criteria: frequency of use, age, and couples. The age bracket (adult gamers) is an under-researched one in gaming, in which the focus has tended to be on young people or children and new media (Buckingham, 2007, 2008; Carr, Buckingham, Burn, \& Schott, 2006; Cassell \& Jenkins, 1999; Livingstone, 2003; Walkerdine, 2006). The frequency of use was an essential parameter as the study strived to examine a phenomenon that was embedded in everyday life, and therefore regular use of the phenomenon was fundamental. Finally, couples were chosen because most women are introduced to MMOs through a male relationship (Jenson \& de Castell, 2010), and $2 / 3$ of all female gamers in MMOs play alongside their romantic partners (Yee, 2008). This knowledge made the couples category interesting: why do women start gaming with their partners, and what keeps them interested in continuing? To shed light on the subject, these data were triangulated with offline observations of gamers' physical gaming set-ups in their homes (Toft-Nielsen, 2012).

The participants were recruited from the same European WoW server, and the focus group interviews lasted between two and four hours. These interviews were semi-structured, using a few core research questions because we wanted to facilitate discussions and negotiations among group members. By combining these methods, we were able to obtain and compare the players' subjective perceptions and negotiated attitudes (the focus groups), and how they framed their gaming practices (the offline observations). In this instance, 'framing' refers to the physical set-up of computers, chairs, etc., used by the participants. The insights produced through these methods are by no means meant as a 
representative and complete picture of how adults engage in gaming, but are rather to be understood as "a specimen" of the intersections between gaming and a wide array of other practices that intersect here: "A specimen as a form of research material is not treated as either a statement about or a reflection of reality; instead, a specimen is seen as a part of the reality being studied" (Alasuutari, 1995, p. 63). Yin further asserts the idea that case studies are only "generalizable to theoretical positions and not to populations or universes" (Yin, 2002, p. 10). That is, the purpose of such studies is to expand theory, not statistical generalization. Through this method, we want to highlight how practices are performed, produced and articulated within and around a net of interrelated practices that pertain to the field of gaming.

\section{The field of gaming and gaming capital}

Games have infiltrated popular and academic awareness to an unprecedented level, and policy makers, the media, organizations, and scholars are now considering how games might offer insight into fundamental questions about human society and activities. However, often this understanding of what games are (and are not) capable of, hinges on an exceptionalist and normative view of what games are, seeing them as fundamentally separable from everyday life (Huizinga, 1970). Such a conceptualization frames games as a subset of play and, as such, views gaming as culturally sequestered, consequence-free activities that are safe, and unproductive (Caillois, 1961). Resent research into computer games has moved away from this dichotomy to now include the gamers, and in particular, what gamers are 'offered' by the games they play (King \& Krzywinska, 2006), what the game 'does to' the gamers (Perron \& Wolf, 2008), more specifically to the gamers' bodies (Gregersen \& Grodal, 2009), and their cognitive and emotional engagement (Genvo, 2009; Järvinen, 2009) as the site of affect, or at least effect. This vein of research is often the preserve of a technologically determined or media-centric approach, with the user's experiences and activities being located elsewhere in the matrix of the new media being explored (see, e.g. Newman, 2005, 2008; Thornham, 2011). This conceptualizes gaming along very specific lines: as solitary, finite, and something done to the gamer by a powerfully affective medium. What is missing here, is attention to the fact that, "the context in which the game is played affects and shapes its value" (Newman, 2005, p. 38). Games are, in other words, intimately connected with aspects of everyday life, and what we commonly consider to be the constitutive features of games are not inherent, but always cultural accomplishments that are specific to a given context (Malaby, 2007).

Games and gaming can be understood as a cultural field (Bourdieu \& Johnson, 2003), in which perceptions and dispositions are aligned with objects and identities, and through which a new cultural proving ground is created. Bourdieu insisted that we cannot analyse sociological processes without first relating them to what goes on in a specific field of practice, in which particular forms of capital are at stake (Couldry, 2013, p. 6). One form of capi- 
tal that is specific to the field of gaming, is what game researcher Mia Consalvo has termed "gaming capital" (2007). Consalvo has studied a broad range of computer game player behaviour and introduced the concept of gaming capital, "to capture how being a member of game culture is about more than playing games or even playing them well" (Consalvo, 2007, p. 18). Gaming capital is a useful, though at times elusive concept, for thinking about what information gamers value, and how this information attains its value. The concept is a reworking of Bourdieu's cultural capital for the field of gaming. Cultural capital refers to knowledge that confers social status and is accumulated through upbringing and education, and it has been used as a lens to "explore social distinctions and codes of 'authenticity' within gaming, such as how male gamers may utilize their understanding of gaming practices and cultures to exclude females" (Rutter and Bryce, 2006, p. 155).

Bourdieu's original schema moves away from rigid categorizations and linear models of the social structure, and by applying Bourdieu to the field of gaming, Consalvo recontextualizes cultural capital as gaming capital. The main virtue of the concept is how it highlights that meaning and values are produced not through battles, but rather through negotiation and contestation between various actors in specific situations and conditions under which game play takes place. Seen in relation to field theory, we understand gaming capital as a resource that gamers hold and negotiate in specific social situations. As we noted earlier, we turn to practice theory because we do not perceive the field of gaming as a field in which winning is necessarily at stake. Nevertheless, as a resource, "gaming capital is distinct in that the contact, knowledge sharing, negotiations, and contextualizations all have face-to-face and live components that engender social contacts, extending outside of the time and space of play itself" (Apperley, 2009, p. 71). This social aspect of gaming capital will be elaborated upon in the empirical analysis. We find that the concept offers a way to examine the network of player activities together, and how these are connected to, and informed by, the contexts in which gaming takes place, most notably, the context of our everyday lives. Gaming capital is used in an attempt to broaden the scope of what matters to participants in gaming practices, and how these values are produced and sustained in interaction with other players and other practices. The concept is "important for understanding the process of play because it points to both the importance of a media ecology and a local sociology of videogame play" (Walsh \& Apperley, 2009, p. 5). This will serve as a framework for constructing a more detailed practice theoretical approach, which we will extrapolate and expand upon in the following section.

\section{A theoretical practice approach to everyday life and gaming}

A theoretical practice approach refers not to a coherent theory, but a particular understanding of an assemblage of theoretical components that aim to conceptualise the organisation of performativity in everyday contexts (Shove et al., 2012; Reckwitz, 2002; Schatzki, 2002; Warde, 2005). Such an approach starts not with media texts or media institutions, 
but from "media-related practice in all its looseness and openness. It asks quite simply: what are people [...] doing in relation to media across a whole range of situations and contexts?" (Couldry, 2012, p. 37). In the following, we want to show how a theoretical practice approach shifts the analytic focus away from a media-centric understanding of games, towards the micro-processes of the practices that integrate gaming and that are integrated into gaming as one element among many others. Our understanding of practice is based on Andreas Reckwitz's definition:

\begin{abstract}
A 'practice' (...) is a routinized type of behaviour which consists of several elements, interconnected to one another: forms of bodily activities, forms of mental activities, 'things' and their use, a background knowledge in the form of understanding, know-how, states of emotion and motivational knowledge. A practice - a way of cooking, of consuming, of working, of investigating, of taking care of oneself or of others, etc. - form so to speak a 'block' whose existence necessarily depends on the existence and specific interconnectedness of these elements, and which cannot be reduced to any one of these single elements. (Reckwitz, 2002, pp. 249-250).
\end{abstract}

The complexity of a practice, which the above quote elucidates, and the fact that different everyday practices intersect and mingle with each other across fields, remain a challenge when we set out to study everyday practices such as gaming (Couldry, 2004). Accordingly, we have to work with two interconnected levels when analysing practices: the specific activity (doings) and its representations, and how the practitioners understand this activity (sayings). Together, sayings and doings constitute the nexus of a practice. This nexus is kept together and coordinated through three elements: 1) understandings 2) procedures, and 3) engagements (Warde, 2005, p. 134). Understandings entail practical understandings and interpretations of what and how to do something in a particular situation, and they involve both physical and mental activities. ${ }^{2}$ The procedures in the nexus are "formulations interjected into social life for the purpose of orienting and determining the activity" (Schatzki, 2002, p. 80), and procedures cover instructions, principles and rules of 'how to do.' Engagements are emotional and normative alignments of activities related to 'what' and 'how to do.' These three components form the nexus of a practice, and practices have to be enacted to reproduce the nexus: "Practices are thus coordinated entities but also require performance for their existence. A performance presupposes a practice" (Warde, 2005, p. 134). The performance is carried out by individuals who are then seen as carriers of the practice.

A key component in working with practice theory and gaming is the role that 'things,' technologies, and material structures play (Reckwitz, 2002; Schatzki et al., 2001). Schatzki (1996) does not consider material structures, 'things,' or technologies important features in keeping a practice together. However, he does understand these as an outcome of social practices. In our context of gaming practices, this perspective is problematic. First, gaming practices are directly facilitated by technology (the computer, gaming software, commu- 
nication software, etc.). The gaming practices occur as a result of these, not the other way around. Second, the material structure surrounding gaming, for example the physical set-up of the computers in the couples' homes, are important components for comprehending how they engage and enact their gaming practices. Consequently, in our understanding of practice theory, we have to supplement Warde's three components (understandings, procedures, and engagements), with a fourth element: material structures and technology. Another essential element in a practice is the role that social interaction plays. Reading Reckwitz (2002), it appears that he argues that practices are carried out by isolated individuals, not together with, and in relation to others. In our analytical case of gaming, social interaction is, among other places, embedded in the material structure (the physical computer set-up in the home) and technologies (Skype-like communication software such as Ventrillo or TeamSpeak that the gamers use). However, to make practice theory operational in empirical analysis, it is necessary to stress social interaction as a fifth constitutive component in line with the previous four. To support our empirical analysis in the following section, we sum up the theoretical points from this section in the practice model below. By placing the bodily-mental activities in the centre, we emphasize that these are the cores of practices.

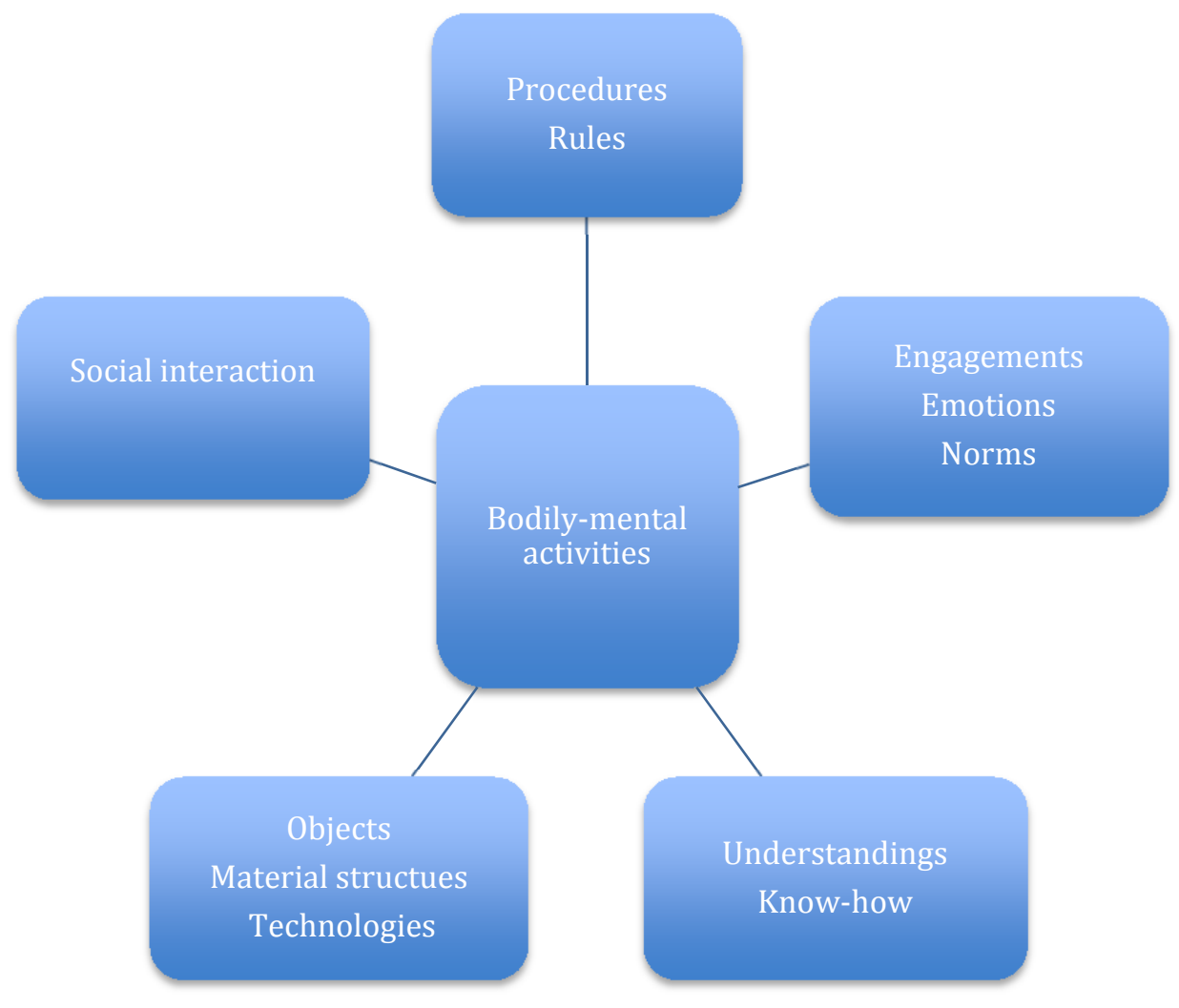

Figure 1: Elements of a Practice 
The model illustrates a single practice, however any given practice exists in interconnectedness with other practices. That is, no practice is hermetically closed. Rather, they intersect with other practices in a constant interaction of innovation and imitation, "... at their widest expanse, they form an immensely complex overall nexus of practices and arrangements that connect, overlap, and interpenetrate in a labyrinthine, unsystematic, and contingent fashion" (Schatzki, 2003, p. 195). Obviously, this gives rise to a number of basic questions when working empirically with practices, such as how do we define which practices are more essential and, thus, more framing than others?

For empirical studies, it is important to distinguish between different forms and different levels of practices. Schatzki contributes to greater analytical clarity by first introducing the distinction between two forms of practices: dispersed and integrative. Dispersed practices appear in many areas of social life, such as following rules or explaining things, and skills require a shared and collective practice, which again involve performance in an appropriate context, so that the performance is recognizable as the practice of explaining something or following a specific rule (Schatzki, 1996, pp. 91-92). Integrative practices on the other hand are more complex, as they are founded in and constitute particular domains of social life (Schatzki, 1996, p. 98). Examples of integrative practices include farming, cooking and gaming (which we will elaborate upon in the empirical-analytical part of this article). Integrative practices occasionally involve dispersed practices in specialized forms, "which are part of the components of saying and doing which allow the understanding of, say, cooking practice, along with the ability to follow the rules governing the practice" (Warde, 2005, p. 135).

Second, Schatzki locates three different levels of practices (Schatzki, 2002, pp. 73-74). On a basic level, there are "actions," which are the aggregated doings and sayings of a practice. A gaming session entails a number of different actions, such as turning on the computer, having bought cola and cigarettes, having fed the cat, and ordering takeaway food, before you can sit down and start. A group of actions constitutes the second level of practices, called "tasks." A task could be to minimise the risk of being disturbed or interrupted while gaming, a task that all of the above actions compose. The combination of tasks within the same practice can eventually form a "project." Projects are the third level of practices, and can be the successful coordination and alignment of the many different and contradictory tasks we face in our everyday lives, such as the successful carving out of time slots in which you can devote yourself to gaming. In a similar vein, we can say that 'play' is the dispersed practices that are also found in many other domains of social life, (Huizinga, 1970) as well as a key part of the integrative practice of 'gaming.' This playful dimension of gaming practice may slide into other related media practices, such as watching TV while chatting to friends. Consuming media products is not an integrative practice in and of itself, but a dispersed practice in a set of practices (doings and sayings) related to media, that can include gaming (cf. Warde, 2005). Or, more practically put, using a computer requires us to be able to navigate the interface, load and save, configure certain software programs, use the mouse in a hand-eye coordinated precise manner, and it involves objects, technologies, skills and know- 
how. Whereas this use of the computer previously felt like a project in Schatzki's sense, it has for many people become a routine practice that involves bodily-mental activities of all sorts. The basic use of a computer is a form of $\mathrm{HCl}$ we know from smartphone interfaces, or from programming DVD players or TVs. These activities draw on the same understandings and skills, whereby basic computer use can be viewed as a dispersed practice that, along with other dispersed practices, can form the nexus of an integrative practice such as gaming.

Taking our point of departure in the analysis of different forms and levels of practices is what makes practice theory operational and analytically sensitive towards empirical data. Rather than taking a top-down approach (by first defining the field and then considering what is at stake in this specific field), we instead apply a bottom-up process, in that we analyse practices to be able to define the field of gaming and what is at stake within the field. In doing this, we find that Bourdieu's field theory supplies the macro-theoretical frame and serves as our way of opening up the empirical data by analysing the practices that constitute the field, as described above and explicated below.

\section{Empirical analysis}

\section{- dispersed and integrative practices in and around gaming}

As with other technologies, integrating the PC into individuals' and couples' everyday lives involves a double-sided process of domestication, in which the technology is adapted to everyday life (Silverstone, Hirsch, \& Morley, 1991), at the same time that everyday life is adapted to technology (Aune, 1996). Following this line of thinking, we examine more closely how gaming as a practice is by no means limited to the individual's consumption of specific computer games, but also involves understanding how the activity of using the computer and the practice of gaming are integrated into and related to other activities, other media, and other practices involving the computer, and how these activities and practices are socially organized. We will discuss a number of integrative practices that all involve the use of games, and where better to start than the interview participants' very first introductions to gaming itself?

Despite the individual differences between the interview participants and the interviews themselves, two ubiquitous tendencies emerged. First and foremost, the interviewees were very experienced gamers, spending between 30 and 60 hours a week in front of the computer, and second, all women were introduced to gaming by either their boyfriends, husbands or sons. The interviews also revealed two different discourses for what motivated the participants to start playing games in the first place. Whereas the men all told stories of starting WoW because of an interest in the game itself, the women's motivations were quite different. Forty-year-old Sharon's introduction to gaming was "playing with the children on their consoles. [...] I would play anything with my children." Thirty-two-year-old Lykke told how she "was introduced by my ex...he was a system administrator so he had to sit by a computer 24 hours a day...So I might as well do that also, so he bought me Neverwinter 
Nights and from that moment on, I was sold." Twenty-one-year-old Line echoes this when she tells of her introduction:

\begin{abstract}
Well I used to think it was a shitty game. I had been living with Morten for quite some time and he sat out there and I sat in here in front of the TV. Sometimes I'd go out to him and look at his computer screen and I had no clue what was going on. And when we had Thomas and Lykke over for dinner, they all talked about the game and I was not in on the conversations and still had no idea what was going on. So I made a deal with Morten... He didn't want to become a blood donor on principle, so if he gave blood, I would try the game. So I started to play.
\end{abstract}

These quotes highlight the fact that the women started to play computer games not because of the games themselves, but in order to spend time with their children, a boyfriend or a husband. Despite the fact that games function fundamentally differently from than other media, owing to the complex levels of interaction between player and game (what is normally termed "game play" (Dovey and Kennedy, 2006, p. 6)), games are also social devices. Additionally, when looking at gaming through the lens of practice theory, we deliberately downplay the interactive nature of games as new media, instead viewing them as material structures and technology, and as part of specific social practices. We are interested in gaming as an activity in a larger practice, not in games as objects. Following Bird's argument, that we need to study the role of media in our culture by focusing on how media outlets are embedded in everyday communicative and cultural practices (Bird, 2003), we view gaming as a social practice that extends well beyond the actual moment of game play. As such, it is both inclusive and excusive, and in order to be included, the women started playing the game. As Line's quote highlights, her becoming a gamer was negotiated with Morten's becoming a blood donor, a negotiation that was completely unrelated to gaming but nevertheless demonstrates an instance of gaming capital negotiation that intersected with their relationship and other forms of cultural capital. As the women start to play the game, their partners encourage them, as well as helping out with the difficulties the women encounter. This gendered power dynamic is yet another instance of gaming capital in use, in that one person with gaming capital teaches another while at the same time maintaining a relationship. Here, playing the game acts as a dispersed practice, and the use of the game console or the PC functions as an object or a technology in the overall, socially organised, integrative practice of doing either 'parenthood' or 'relationship.'

Another practice related to those mentioned above is one we may call 'hanging out.' This practice highlights the importance of how mediated communication technologies can support the continuous production and reproduction of close and meaningful relationships. The two British women Sharon and Kirsten play in the same guild of fifty-some players nearly every night and participate in the same in-game activities as the other guild members, however the way they do it is special. Both women tell the story of how gaming slots into and takes away time they used to spend watching TV. Kirsten explains: "I don't really watch much TV because...before I moved, the TV used to be in a different room 
from the computer. So I kind of stopped watching TV while I was playing. I have now got a TV next to my computer. However, apart from watching the occasional part of $X$-Factor and chatting to Sharon about it in the middle of the raid, I don't really tend to watch that much." Both Kirsten and Sharon are so skilful at playing the game that they can devote their attention to other things during gaming, such as watching TV and chatting to each other via third-party communication software, while still participating in the same in-game activities as the rest of the guild members.

By zooming out from what happens in-game online, we see another practice that emerges from just gaming. Here, the TV, the computer and the communication software allow the women to use them in a way that functions as material elements in the social and mediated practice of 'hanging out' with a friend. The technology of the PC facilitates a gaming practice in which they engage: Having played the game for so long, they now have an habitual understanding and know-how of it, extensive knowledge of the game's procedures, and engage in the sociality of the guild members with whom they play. All of these elements form the nexus of the practice of online gaming. However, there is a second layer to this because online gaming has now become an internalised, routine, mind-body activity for Sharon and Kirsten; it has become a dispersed practice. Using the game, the TV, and the communication software in conjunction with each other functions on one level as both technologies and activities (playing the game, interacting with in-game friends, watching TV, chatting with each other) in multiple dispersed practices. These practices, together with procedures, engagements, and the social interactions, form the nexus of the integrative practice of 'hanging out' with a friend. Both women highlight the social interaction and the everyday talking with each other as one of the primary reasons for spending so much time gaming, which is why we consider 'hanging out' one of the primary social practices at work here. This suggests an important aspect of a practice theory approach, namely, that the same activities can be interpreted as being part of multiple interrelated and overlapping practices.

The final examples we include are the couples who game together. As mentioned above, it can sometimes be difficult to juggle all of the different tasks, chores and practices in our everyday lives, especially if we also want to carve out time to invest in gaming. To spend more time together, all three couples in each of their homes had arranged their physical gaming set-ups so that they sat side by side, next to each other. These arrangements highlight the importance of including both the material structures and social interactions in the analysis of a practice because these set-ups allowed them to be together, both in-game and physically out-of-game, as the following conversation shows:

Lykke: "My parents have asked me why Thomas and I didn't spend more time together, watching TV or something..."

Line: "But, it's the same thing!"

Morten: "Yes it is" 
Lykke: "It is the same! Whether we are sitting on the couch watching TV or we sit next to each other at our computers - I can't see what the difference is."

Line: "Well, apart from the fact that we can't hold hands while gaming..."

As the women started to play together with their partners, the game itself became an activity they shared, something they did together. Despite the fact that playing a game and watching TV require quite different skill sets, the couples came to understand them as similar because of their social functions. Here, mediated and non-mediated interactions intertwine as the couples engage in and perform two simultaneous, socially organised practices: gaming and relationships. Both their doings (how the couples created set-ups that allowed them to do things together both in-game and physically out-of-game), and their sayings (how they explicitly articulate, compare and understand their co-gaming practices to sitting together on the couch and watching TV together), reflect this. The computer has here created a new possibility for situations of 'togetherness' that draw on some of the same elements, understandings and engagements as the practice of watching TV. Thomas draws on a similar, but slightly different media practice, when he describes a typical evening of gaming for Lykke and him:

\footnotetext{
Lykke: "We make sure to have a full stock of beer and soft drinks and if you want candy, remember to buy it... and enough cigarettes to last the evening..."

Thomas: "And remember to feed the cats..."

Lykke: "Yeah the cats... and emptying the cat tray."

Thomas: "Well, it's like a visit to the cinema for a double-length film. [...] You have to have your popcorn, you have to have your soft drink, you have to remember to go to the toilet before the film, 'cause it's $2 \frac{1}{2}$ to 3 hours we are talking about, you have to remember to smoke before you go in, and you must remember to turn off your mobile phone before... 'cause your parents could be calling you while you play, and we don't want that [...]. All these things, it's just like a visit to the cinema really."
}

Rather than being a new and unique practice, the couples' gaming practices make extensive use of some of the same procedures, norms, know-how, and objects from other similar entertainment-oriented practices. The candy, soft drinks, popcorn, remembering to go to the toilet, to stock up, to feed the cat, to turn off the mobile phone, together with the physical set-up next to each other, are all loans from the practice of 'visiting the cinema,' elements that are then re-integrated into the practice of 'gaming.' In Schatzki's sense, we could say that the doings and sayings are the actions, which work together to form an overall task of minimising the possible distractions or interruptions that could occur during gaming. The overall combination of tasks with the same practice constitutes a project, in this case the successful coordination, balancing and alignment of 'doing a relationship' in proportion to other competing and intersecting practices in our everyday lives. The computer has, in other words, created a new frame for the production and reproduction of relationships, of carving out time to 'be together.' The integration of the computer as a new material element has contributed to what we might call a reconstitution of the practice of 'doing 
relationships,' where the computer has replaced both the social function and the context of use that other, more traditional media such as the TV, the radio, or film previously held. The daily planning, coordination and negotiation of different tasks, chores and practices in our everyday lives are closely interwoven with the interview participants' gaming practices. When they discussed the difficulties of coordinating gaming, the relationship, work, and daily chores, Thomas summed it up by saying: "Well, you want everything to form a whole and to go in the same direction." "To form a whole," and "to go in the same direction," exactly reflect coordinating activities and practices in such a way that everything fits with the anchoring practice of everyday life. This forms the overall project for the couples, as they assemble different and previously contradictory practices - gaming, and the relationship - in the practice of doing both at the same time.

\section{Concluding remarks}

A practice-based approach has opened up broad questions about the sorts of things people are regularly doing with media, amid the proliferating complexity of digital media and everyday life. Adopting such an approach, has proven to be a more integrated and holistic path towards a social understanding of media and technologies. This has implied a change of paradigm in media studies because it changes the focus of media research from the semiotic analysis of text content and frames its questions by reference, not to media as objects, texts, or apparatuses of perception, but to what people actually do and say in relation to media. The practice-based approach has highlighted the interconnectivity of the use of technologies involved in media consumption, as it moves away from understanding media consumption as fixed types, and reframes consumption to continuous, relational accomplishments in multiple, intersecting everyday life practices.

A practice theory approach adds more detail and nuances to the empirical analysis, and has the potential to better enable us to understand long-term perspectives related to changing media consumption patterns. Focusing on a specific practice such as gaming in this case, a phenomenon embedded in the context of everyday life, emphasizes in more detail the dynamic intermingling of media, technological, social and discursive changes. As described initially, this method of approaching the analysis makes room for detecting the transversal effects across the field of gaming and other related social fields (e.g. relationships), an area that field theory does not appear to acknowledge. We have seen how changes in specific kinds of media consumption have allowed for new types of socialites, new possibilities of doing 'togetherness,' and new forms of practices that grow out of the activities and elements of older, earlier practices. As Warde (2005) has argued, one of the strongest points of applying a practice theory approach in studies of consumption and everyday life (in our case, media consumption in general, and gaming in particular), is that people do not think of themselves as consuming but rather as doing different things: 
gaming, chatting, preparing dinner, hanging out, etc. Consumption then follows as an integral result of these things because it emerges as a result of practices.

The combination of Bourdieu's field theory as a theoretical and conceptual macroframe, along with the analytically more sensitive micro-analysis of practices, contributes to the development of a practice theory approach by exploring and expanding some of the issues that arise when practice theory is applied in empirical studies. Couldry (2003) and Panofsky (2011) argue that field theory leaves unanswered questions about the limits, overlaps and interrelations of fields. Turning to the practice approach enables us to scrutinize the field of gaming, its overlaps and its interrelations In other words, practice theory supplies the tools for empirically scrutinizing a field constituted by its numerous intersecting practices. In relation to computer games in general and online computer games in particular, Hjorth calls for a reflexive and revised use of theories because, "we can find a plethora of different instances of social capital that highlight the need to revise models provided by Bourdieu" (Hjorth, 2011, p. 60). We hope to have taken a small step towards modifying the way models and concepts of field and practice are used in empirical analysis.

\section{References}

Alasuutari, P. (1995). Researching culture: qualitative method and cultural studies. London: Sage.

Apperley, T. (2009). Gaming Rhythms: Play and Counterplay from the Situated to the Global. Theory on Demand. Amsterdam: Institute of Network Cultures.

Aune, M. (1996). 'The computer in everyday life: Patterns of domestication of a new technology'. In Lie, M. and Sørensen, K. (Eds) Making Technologies Our Own? Domesticating Technology into Everyday Life , Oslo: Scandinavian University Press, 91-120.

Bird, E.S. (2003). The Audience in Everyday Life: Living in a Media World. New York: Routledge.

Bourdieu, P. (1977). Outline of a Theory of Practice. New York: Cambridge University Press.

Bourdieu, P. (1984). Distinction: A Social Critique of the Judgement of Taste. Cambridge: Harvard University Press.

Bourdieu, P., \& Johnson, R. (2003). The field of cultural production: essays on art and literature (Reprinted. ed.). Cambridge: Polity Press.

Bourdieu, P. \& Wacquant, J.D. (1992). An Invitation to Reflexive Sociology. Cambridge: Polity Press.

Bräuchler, B., \& Postill, J. (2010). Theorising media and practice. New York; Oxford: Berghahn.

Buckingham, D. (2007). Beyond technology: children's learning in the age of digital culture. Cambridge: Polity. Buckingham, D. (2008). Youth, identity, and digital media. Cambridge, Mass.: MIT Press.

Caillois, R. (1961). Man, play, and games. New York: The Free Press of Glencoe.

Carr, D., Buckingham, D., Burn, A., \& Schott, G. (2006). Computer games: text, narrative and play. Cambridge: Polity.

Cassell, J., \& Jenkins, H. (1999). From Barbie to Mortal kombat: gender and computer games (2. printing. ed.). Cambridge, Mass.: MIT.

de Certeau, M. (1984). The Practice of Everyday Life. California: University of California Press.

Consalvo, M. (2007). Cheating: gaining advantage in videogames. Cambridge, Mass.; London: MIT Press. 
Couldry, N. (2003). 'Media meta-capital: Extending the range of Bourdieu's field theory'. Theory and Society, 32(5-6), 653-677.

Couldry, N. (2004). 'Theorising media as practice'. Social Semiotics, 14(2), 115-132.

Couldry, N. (2012). Media, society, world: social theory and digital media practice. Cambridge: Polity.

Couldry, N. (2013). 'Mediatization and the Future of Field Theory'. Working paper No. 3. Bremen: Communicative Figurations Research Network.

Dovey, J., \& Kennedy, H.W. (2006). Game Cultures: Computer Games As New Media. McGraw-Hill International.

Foucault, M. (1978). The History of Sexuality. Vol. 1 Harmondsworth: Penguin.

Genvo, S. (2009). 'Understanding Digital Playability'. In B. Perron \& M.J.P. Wolf (Eds.), The video game theory reader 2. New York: Routledge, 133-149.

Giddens, A. (1979). Central Poblems in Social Theory. Action, Structure and Contradiction in Social Analysis. California: California Univeristy Press.

Giddens, A. (1984). The Constitution of Society. Cambridge: Polity Press.

Gregersen, A., \& Grodal, T. (2009). 'Embodiment and Interface'. In B. Perron \& M.J.P. Wolf (Eds.), The video game theory reader 2. New York: Routledge, 65-83.

Halkier, B., \& Iben J., (2008) 'Det sociale som performativitet - et praksisteoretisk perspektiv på analyse og metode'. Dansk Sociologi 19(3), 49-68.

Hjorth, L. (2011). Games and gaming: an introduction to new media. Oxford: Berg.

Huizinga, J. (1970). Homo Ludens: a study of the play element in culture. London: Temple Smith.

Jenson, J., \& de Castell, S. (2010). 'Gender, Simulation, and Gaming: Research Review and Redirections'. Simulation \& Gaming, 41(1), 51-71.

Järvinen, A. (2009). 'Understanding Video Games as Emotional Experiences'. In B. Perron \& M.J.P. Wolf (Eds.), The video game theory reader 2. New York: Routledge, 85-108.

King, G., \& Krzywinska, T. (2006). Tomb Raiders and Space Invaders: Videogame Forms and Contexts.

LeBesco, K. \& Naccarato, P. (2012). Culinary Capital. New York: Berg.

Livingstone, S. (2003). Young people and new media: childhood and the changing media environment (2. printing. ed.). London: SAGE.

Malaby, T.M. (2007). 'Beyond Play'. Games and Culture, 2(2), 95-113.

Newman, J. (2005). Videogames (Reprint. ed.). London: Routledge.

Newman, J. (2008). Playing with videogames. London; New York: Routledge.

Postill, J. (2010). 'Introduction: Theorising Media and Practice'. In Bräuchler, B., \& Postill, J. (Eds.) . Theorising media and practice. New York; Oxford: Berghahn, 1-32.

Panofsky, A.L. (2011). 'Field analysis and interdisciplinary science: Scientific capital exchange in behavior genetics'. Minerva, 49(3), 295-316.

Perron, B., \& Wolf, M.J.P. (2008). The video game theory reader 2. New York: Routledge.

Reckwitz, A. (2002). 'Toward a Theory of Social Practices'. European Journal of Social Theory, 5(2), 243-263.

Schatzki, T.R. (1996). Social practices:a Wittgensteinian approach to human activity and the social. Cambridge: Cambridge University Press.

Schatzki, T.R. (2002). The site of the social: a philosophical account of the constitution of social life and change. University Park, Pa: Pennsylvania State University Press.

Schatzki, T.R. (2008). Social practices: a Wittgensteinian approach to human activity and the social (Digitally printed ed.). Cambridge: Cambridge University Press.

Schatzki, T.R., Knorr-Cetina, K. \& von Savigny, E. (2001). The Practice Turn in Contemporary Theory. New York: Routledge. 
Silverstone, R., Hirsch, E., \& Morley, D. (1991). 'Listening to a long conversation: An ethnographic approach to the study of information and communication technologies in the home'. Cultural Studies, 5(2), 204-227.

Swidler, A. (2001). 'What Anchors Cultural Practices'. In T. Schatzki, K. Knorr Cetina \& E. von Savigny (Eds.) The Practice Turn in Contemporary Theory. London: Routledge,.

Thornham, H. (2011). Ethnographies of the videogame: gender, narrative and praxis. Farnham: Ashgate Pub. Company.

Toft-Nielsen, C. (2012). Gamingpraksis: en vidvinkeloptik på computerspil, køn, genre og hverdagsliv. Institut for Æstetik og Kommunikation, Informations-og Medievidenskab.

Wacquant, L. (1989) 'A workshop with Pierre Bourdieu', Sociological Theory, 7(1), 26-63.

Walkerdine, V. (2006). 'Playing the game: Young girls performing femininity in video game play'. Feminist Media Studies, 6(4), 519-537.

Walsh, C. \& Apperley, T. (2009). 'Gaming capital: Rethinking literacy', refereed conference paper from the proceeding of the Australian Association for Research in Education 2008 conference: Changing Climates: education for Sustainable Futures (Brisbane, Australia, December 2008)

Warde, A. (2004). 'Practice and field: revising Bourdieusian concepts'. CRIC Discussion Paper No 65. Manchester: Centre for Research on Innovation \& Competition.

Warde, A. (2005). 'Consumption and Theories of Practice'. Journal of Consumer Culture, 5(2), 131-153.

Yee, N. (2008). 'Maps of Digital Desires: Exploring the Topography of Gender and Play in Online Games'. In Y.B. Kafai (Ed.), Beyond Barbie and Mortal Kombat: New perspectives on gender and gaming. Cambridge, Mass.; London: MIT.

\section{Notes}

1 For a more elaborate description of the empirical study, see Toft-Nielsen, 2012.

2 This category of understanding connects closely to Bourdieu's habitus, which he describes as: "a system of lasting, transposable dispositions which, integrating past experiences, functions at every moment as a matrix of perceptions, appreciations, and actions, and makes possible the achievement of infinitely diversified tasks, thanks to analogical transfers of schemes permitting the solution of similarly shaped problems" (Bourdieu, 1977: 83).

Claus Toft-Nielsen

Ph.D., Research Assistant

Department of Aesthetics and Communication \& Centre for Teaching Development and Digital Media University of Aarhus, Denmark imvctn@dac.au.dk

Stinne Gunder Strøm Krogager

Ph.D., Assistant Professor

Department of Communication

Aalborg University, Denmark

stinne@hum.aau.dk 